\title{
Research on Differences of Fairness of Educational Resource Allocation between Urban and Rural Areas in China
}

\author{
Wenjing Wang \\ Department of Politics and Law, Northeast Normal \\ University \\ Changchun, P.R. China 130117 \\ wangwj672@nenu.edu.cn
}

\author{
Ye Tao \\ Department of Politics and Law, Northeast Normal \\ University \\ Changchun, P.R. China 130117 \\ Taoy185@nenu.edu.cn
}

\begin{abstract}
After constructing the urban and rural compulsory education fairness index, the authors calculate the urban and rural compulsory education fairness index scores of 31 regions from 2010 to 2014 to study the differences of fairness of urban-rural educational resource allocation. The results show that most provinces make a great step forward in urban and rural compulsory education equity, but the regional difference is still prominent. We also discuss the two main determinants of it, urban and rural economic development gap and provincial fiscal system, it comes to conclusion that provincial fiscal decentralization plays the most important role in regional difference in urban and rural compulsory education fairness.
\end{abstract}

Keywords-urban and rural compulsory education fairness index; education gap; regional difference; provincial fiscal decentralization

\section{INTRODUCTION}

Education fairness is an extension of social equity in the field of education, which consists of urban-rural equity, gender equity, national fairness, social class fairness and other dimensions [1]. Among them, urban and rural education differences have become an important aspect of China's education inequity. In 2010, the National Education Reform and Development of Long-term Planning Programs takes building a basic public education service system covering urban and rural areas, achieving equalization of basic public education services, narrowing the regional gap as the basic realization of education modernization, the basic form of learning society, and the strategic goal of entering the ranks of human resources by 2020 .

The formation of urban and rural education gap in China has profound historical and social reasons. A series of urban and rural dualistic institutional arrangements based on the household registration system are the institutional roots of urban and rural education differences [2]. Hidden behind the household registration system, the education, health care, social security and other public goods discrimination policy constitutes an important urban and rural education development of important institutional constraints [3].

This research was financially supported by the 12th Five-years Plan of National Science of Education of Ministry of Education Youth Program(Grant No.: EGA130390), Fundamental Research Funds for the Central Universities and Science and Technology Development Project of Jilin Province(Grant No.:20140418027FG)
Although faced with similar institutional constraints, education equity between urban and rural issues in different regions has different performance. It is possible to provide information support for the formulation of policies for the development of urban and rural education, to establish the fairness index of urban and rural education, to compare the level of educational equity in each region and to analyze the causes of unfairness.

\section{METHODOLOGY}

Education fairness is an important part of educational development. The educational equity indicator is used as a core indicator of statistical system in World Bank, OECD and other international organizations [4]. There have been lots of research papers other educational developmental index, while education equity has not been taken into final index calculations. Although some scholars have put forward to construct the index system of education fairness, just rough index system [5]. In this paper, we focus on the dimension of education equity of compulsory education between urban and rural area, at the same time in the construction of urban and rural compulsory education fairness index, the score of education fairness is calculated for each region.

\section{A. Indicators Selection}

In the case of sufficient statistical data, the urban and rural compulsory education fairness index should include many measurable indicators of urban and rural education differences, such as educational opportunities, educational inputs and education results. However, taking into account the availability of data, we only use the four indicators of education investment to construct the urban and rural compulsory education fairness index

- Average education expenditure difference between urban and rural in primary schools, which is expressed as AEDPS.

- Average education expenditure difference between urban and rural in junior high schools, which is expressed as AEDJHS. 
- Difference of full-time teachers' qualifications in primary schools between urban and rural areas, which is expressed as DTQPS.

- Difference of full-time teachers' qualifications in junior high schools between urban and rural areas, which is expressed as DTQJHS.

\section{B. Model specification}

On the choice of the weight of the index, four secondary indicators are given the same weight, all for a quarter. In order to facilitate understanding and regional comparison, the four secondary indicators of fairness index of urban and rural compulsory education are all standardized. It can be expressed in the following:

$$
\mathrm{Z}_{\mathrm{s}}=\mathrm{z}_{\mathrm{i}} / \mathrm{z}_{\mathrm{u}}
$$

Where, $Z_{s}$ is the standardized value of each secondary indicator, $z_{i}$ refers to the actual value of each secondary indicator in each region, $z_{u}$ is the optimal value of each secondary indicator in each region.

It is believed that the ideal condition of education equity should be the rural students at least treated the same as urban students. Whether the allocation of teachers or expenditure, the best standard is no difference between rural and urban areas. That means the optimal value of the four secondary indicators is 1 . When the actual value of rural indicators is closer to the city, the greater of the education fairness index, the fairer of education allocation of urban and rural compulsory education in certain region. When the value of a rural indicator is greater than the urban one, it is not indicated the situation is more equitable, but just be considered of achieving the requirement of ideal education equity. That means the maximum value of difference index of urban and rural compulsory education is 1 .

The computation formula of urban and rural compulsory education fairness index can be expressed in the following:

$$
\mathrm{CEFI}=\frac{1}{4} \times(\text { AEDPS }+ \text { AEDJHS }+ \text { DTQPS }+ \text { DTQJH })
$$

Where, CEFI represents compulsory education fairness index between urban and rural areas.

The computation formulas of second indicators are in the following:

$$
\mathrm{AEDPS}=\min [(\mathrm{RAEPS} / \mathrm{UAEPS}), 1]
$$

Where, RAEPS is average education expenditure of primary schools in the rural, UAEPS is average education expenditure of primary schools in the urban.

$$
\text { AEDJHS }=\min [(\text { RAEJHS } / \text { UAEJHS }), 1]
$$

Where, RAEJHS refers to average education expenditure of junior high schools in the rural, UAEJHS is average education expenditure of junior high schools in the urban.

$$
\text { DTQPS }=\min [(\text { RPCDPS/UPCDPS }), 1]
$$

Where, RPCDPS is the proportion of colleague degree or above of full-time teachers in rural primary schools, UPCDPS is the proportion of colleague degree or above of full-time teachers in urban primary schools.

$$
\text { DTQJHS }=\min [(\text { RPBDJHS/UPBDHS }), 1]
$$

Where, RPBDJHS refers to the proportion of bachelor degree or above of full-time teachers in rural junior high schools, UPBDHS refers to the proportion of bachelor degree or above of full-time teachers in urban junior high schools.

\section{Data resource}

The data used in this article are from China Educational Finance Statistical Yearbook and China Education Statistics Yearbook. The time span is 31provinces during 2010 and 2014 period.

\section{THE COMPARISON OF REGIONAL URBAN AND RURAL}

\section{COMPULSORY EDUCATION FAIRNESS}

We calculate the sores of index of urban and rural compulsory education fairness in the 31 provinces of China for 2010-2014, the top five scores and minimum five sores of urban and rural compulsory education fairness are shown in Table 1.

According to the results in Table 1, the urban and rural compulsory education fairness level has been improved in most of our country from 2010 to 2014. In 2010, the average of urban and rural compulsory education fairness index is 0.859 , while the index score is 0.916 in 2014, which is increased by 0.057 . From the urban and rural compulsory education fairness index of the top five provinces, cities and autonomous regions, the economic development of Tibet, Qinghai and Jilin is behind the developed eastern regions. That indicates that compulsory education fairness is likely to be at a low level in these areas. 
TABLE I. TOP FIVE SCORES AND MINIMUM FIVE SORES OF URBAN AND RURAL COMPULSORY EDUCATION FAIRNESS IN THE PROVINCES OF ChINA (2010-2014)

\begin{tabular}{|l|l|l|l|l|l|}
\hline Province & $\mathbf{2 0 1 0}$ & Province & $\mathbf{2 0 1 2}$ & Province & $\mathbf{2 0 1 4}$ \\
\hline Beijng & 0.986 & Beijing & 0.99 & Tibet & $0.995^{\mathrm{a}}$ \\
\hline Tibet & $0.936^{\mathrm{a}}$ & Zhejiang & 0.966 & Beijing & 0.984 \\
\hline Zhejiang & 0.935 & Tibet & $0.953^{\mathrm{a}}$ & Zhejiang & 0.978 \\
\hline Qinghai & 0.933 & Jiangsu & 0.947 & Jiangsu & 0.95 \\
\hline Jilin & 0.913 & Qinghai & 0.944 & Jilin & 0.945 \\
\hline Jiangxi & 0.826 & Jiangxi & 0.860 & Xinjiang & 0.880 \\
\hline Hubei & 0.813 & Guangdong & 0.847 & Hainan & 0.879 \\
\hline Hainan & 0.813 & Hainan & 0.843 & Hunan & 0.876 \\
\hline Guangdong & 0.711 & Gansu & 0.675 & Jiangxi & 0.872 \\
\hline Jiangsu & 0.665 & Heilongjiang & 0.674 & Guangdong & 0.86 \\
\hline
\end{tabular}

a. Because of the lacking of the data of education expenditure of Tibet in rural junior high schools, the AEDJHS of Tibet cannot be calculated. For this special case, we adjust the computation formula of education fairness index correspondingly. That is, CEFI $=\frac{1}{3} \times($ AEDP + DTQPS + DTQJHS $)$

\section{DETERMINANTS OF FAIRNESS IN COMPULSORY}

\section{EDUCATION IN URBAN AND RURAL AREAS.}

Although the phenomenon of urban and rural compulsory education differences exists generally, from the previous analysis, the differences show different performance. In 2014, the urban and rural compulsory education fairness index scores of 31 provinces lie between 0.86 to 0.99 . Among them, the sores of Tibet and Beijing exceed 0.98, while the lowest score is only 0.86 in Guangdong. In this part we discuss the determinants of urban and rural compulsory education fairness. Index of urban and rural compulsory education fairness reflects the differences in compulsory education investment between urban and rural areas from two aspects of education funds and quality of teachers. Differences of urban and rural compulsory education investment can be concluded into two main reasons, the first one is social and economic development, and the second is management system of the government.

Under the constraint of the urban and rural dual structure, the difference of urban and rural education development is not only an important part to represent social development difference, but a reflection of social and economic development difference between urban and rural areas in the field of education [6]. On the other hand, the compulsory education management system of running and administrating a school by stage, as local public goods provided by local governments, the difference between urban and rural areas directly depends on the government management system, especially the fiscal system of governments.

\section{A. The determinism of urban and rural economic development difference}

The level of economic development determines the level of education development, the differences between urban and rural economic development determines the education fair condition between urban and rural areas to a certain extent.

Economic development is the source of education investment, the vast difference between the urban and rural economic development causes the gap of financial resources of the governments. Under the classification management system of compulsory education in our country, the difference of government financial resources eventually led to the big gap between urban and rural education expenditure. On the other hand, differences between urban and rural economic development also cause the public service between rural and urban areas, career development and potential revenue differences. According to the principle of compensating wage, rural teachers should been paid higher wage to recruit the same quality teachers as those in the urban city. The greater the difference between urban and rural economic development, the higher demands of compensating wage. Under the existing wage system of teachers in our country, we lack compensating wage arrangement. Therefore, it can be expected that regions of urban and rural economic development will lead to greater differences of teachers' quality level.

Since the reform and opening, the economic development gap has been expanding fast between urban and rural areas. By contrast, the difference of urban and rural economic development is slightly less in developed areas than those of in the economic laggard areas. The indicator of urban and rural expenditure ratios which measures differences between urban and rural economic development, shows that the biggest gap of consumption expenditure between urban and rural areas is Tibet in 2014, the value exceeds 4.60, while the smallest gap of consumption expenditure between urban and rural areas is Beijing, the value is only 1.95

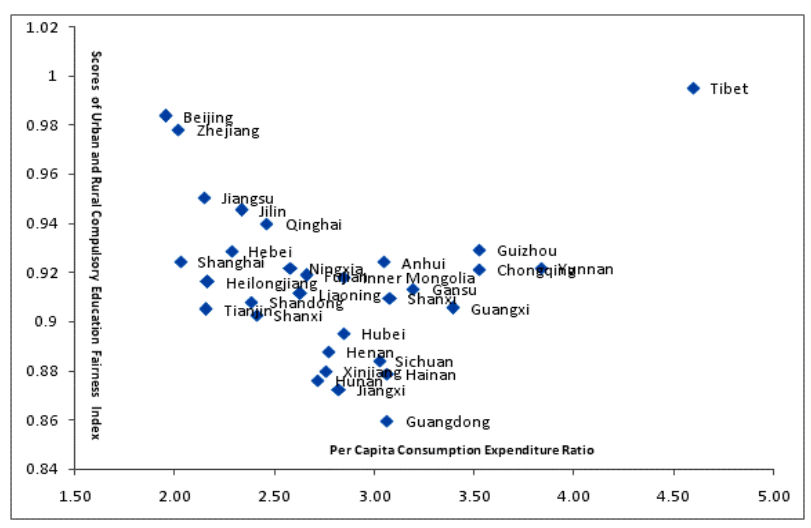

Fig. 1. Scatter of Scores of Urban and Rural Compulsory Education Fairness Index and Per Capita Consumption Expenditure Ratio 
Fig.1 describes the scatter of scores of urban and rural compulsory education fairness index and per capita consumption expenditure ratio. From Fig.1 we can find that regional urban and rural compulsory education fairness index sore is lower when the difference of urban and rural per capita consumption is large. The region where the difference of urban and rural consumption expenditure is larger, the score of urban and rural compulsory education fairness index ranks in the later position, the average ratios of the score of urban and rural consumption expenditure is up to 2.9 .

\section{B. The determinism of the financial system}

In 1994 China began to reform the "revenue-sharing-scheme" financial management system, it established a clear mechanism of income distribution which distinguish three types of taxes, that is central tax, local tax revenue and shared tax between the two levels of government revenue. However, it didn't come up with an income distribution framework under the provincial government, according to the traditional ways of income distribution pattern which is decided by a provincial government.

Different provincial fiscal decentralization has important influence on urban and rural education fiscal health, and education finance system is the guarantee of education development. Therefore, fiscal decentralization in the province is an important factor that affects regional difference between urban and rural education development. County-level government the main rural compulsory education undertaker, the government has the greater financial guarantee rural compulsory education development if it has larger ratio of fiscal expenditure.

\section{CONCLUSION}

In this paper, we calculate the urban and rural compulsory education fairness index sores of 31 provinces from 2010-2014. On the basis of that, we explore the influence of difference of the urban and rural economic development and the financial system on urban and rural education equity. The results indicate that the situation of fiscal decentralization in provinces is the main reason to cause the difference of urban and rural education fairness index scores. The region where provincial total fiscal expenditure proportion is major, the development of rural compulsory education is suppressed, and the development of compulsory education in cities is not improved obviously.

Under the condition of big gap between urban and rural areas, the basic way of narrowing the difference of urban and rural compulsory education, promoting education fairness is to reform the government fiscal system and compulsory education financial system. It comes to the conclusion that we should adjust the provincial, urban and county level distribution of revenue and expenditure, increase the proportion of fiscal expenditure of province and county, and reduce the local fiscal expenditure proportion at the corresponding level.

\section{REFERENCES}

[1] Wenjing Du, and Xinbin Ge, "Dilemmas and strategic choices of overall development of urban and rural compulsory education", Research in Education Development. pp.19-24, September 2016. (In Chinese)

[2] Yongkun Fan, and Zhihui WU, "A research report on balanced development of rural and urban education resource in China", Educational Research. pp.32-44,83,November 2014.(In Chinese)

[3] Huaping Geng, and Zuyun Liu, "The theoretical thinking and realistic attribution of the unbalanced development in urban and rural compulsory education", Nanjing Journal of Social Science. pp.135-139, April 2016.(In Chinese)

[4] World Bank, "World Development Indicators", Washington D.C.: The World Bank,pp.31-34,May 2009.

[5] Yunhua Zhong, Xiaoyuan Li, and Jiang Tang, "The analysis of urban and rural compulsory education equalization from equity perspective", China Agricultural Education. pp.6-11, August 2013.(In Chinese)

[6] Liu, M., and Tao, R., "The political economy of earmarked transfers in a state-designated poor country in western China: central policies and local responses", The China Quarterly, pp.973-994, January, 2009 